\title{
Neonatology specialty grand challenge
}

\author{
John Steven Torday* \\ University of California Los Angeles, Los Angeles, CA, USA \\ *Correspondence: jtorday@labiomed.org
}

\section{Edited by:}

Antonio Francesco Corno, King Fahad Medical City, Saudi Arabia

Reviewed by:

Charles Christoph Roehr, Charité Universitätsmedizin Berlin, Germany

Historically, though high infant mortality rates were recognized by the British medical community at least as early as the 1860 s, the advent of neonatal intensive care is relatively recent. In 1898, Dr. Joseph B. De Lee (1) established the first premature infant incubator station at the Chicago, Illinois Lying-in Hospital. The first American textbook on prematurity was published in 1922 (2). It was not until 1965 that the first American newborn intensive care unit (NICU) was opened at Yale University, but more importantly, only a few years later Egon Diczfalusy conceptualized the fetoplacental unit (3), which established that the fetus actively participates in its own physiologic development in utero. This represented a fundamental break with Victorian attitudes toward maternal confinement during pregnancy, and set the bar for reproductive physiology to this day.

Such breakthroughs as Helen Taussig's surgical approach to the treatment of the Tetralogy of Fallot (4); the Liley Score for hyperbilirubinemia (5); the L/S ratio (6), Continuous Positive Airway Pressure ventilation (7), antenatal steroids (8), and postnatal exogenous surfactant to prevent and treat Respiratory Distress Syndrome (RDS) (9) all led inexorably to the fetus as a patient. It was the advent of antenatal steroids for lung immaturity that was the call to action for the Neonatology Community - the realization that there was a way to proactively affect the outcome of preterm birth, not merely passive watchful waiting (For example, Dr. Gluck's dictum that if the L/S ratio were less than 2:1, to wait for 2 weeks and retest). That challenge set the bar, and it remains to this day, given all of the ancillary effects of antenatal steroids on multiple organs and systems.

The origins of Neonatology as a formal discipline were sown by investigators passionately curious about the limits of human physiology. Clement Smith would relate his story of how he and his pediatric colleagues were allowed to round on preterm infants at the Boston Lying-In Hospital in the 1950s, initially observing, and then providing minimal nourishment (a little glucose on the tongue) and comfort (warming lamps). One of Professor Smith's more ambitious, forward-thinking, and observant Fellows, ME Avery, would express to her students how dissatisfied she was with the diagnosis of Hyaline Membrane Disease (HMD) as an inevitable post-mortem consequence of pulmonary obstructive disease. Instead, she took the initiative of studying lung surfactant in these infants, hypothesizing that they were surfactant deficient. She and Jere Mead demonstrated that the lung washings of preterm infants who died of HMD were deficient in surface tension-reducing activity in their airways (10), subsequently championing one of the first U.S. clinical trials for the use of antenatal glucocorticoids to stimulate lung surfactant production, following on the first clinical use of antenatal glucocorticoids by Liggins and Howie in New Zealand (11). As a result of this intervention, the mortality rate due to RDS among infants less than 32 weeks gestation fell dramatically, but the morbidities of preterm birth - bronchopulmonary dysplasia, necrotizing enterocolitis, retinopathy of prematurity, intraventricular hemorrhage, cerebral palsy - necessarily increased as a direct result of the increased survival, leaving the newly established discipline of Neonatology with the tandem challenges of further reducing morbidity, while deciphering the underlying principles of physiology to predict and prevent the sequelae of preterm birth.

There is a long history of systematic approaches to determining where along the normal course of development any given preterm infant is at the time of birth. In 1952 Dr. Virginia Apgar described the Apgar scoring system (12) as a formalized means of evaluating a newborn's physiologic condition at the time of birth. And then there were Lula Lubchenko's standardized birthweights (13), which provided objective data for calibrating gestational age at birth. More recently, Doug Richardson (14) had devised the SNAP score. All of these efforts are designed to try and circumscribe the emergent and contingent character of preterm birth, much like the description of the process of Evolution itself, which has been equally elusive for the very same reasons. Identifying the predictors of neonatal physiology and well-being remains a challenge.

The only advance in Neonatology based on a priori scientific principles of fetal physiology and adaptation was the discovery by Avery and Mead (10) that RDS was due to lung surfactant deficiency at birth. All of the other treatments and procedures were derived a posteriori from standard pediatric physiology reduced to its application to the preterm newborn. Over time, the discipline became aware that preterm infants are not merely small term infants, they are fetuses who have not achieved their full physiologic capacity. We have yet to discover the underlying cause of preterm birth, or the fundamental phylogenetic mechanisms of adaptive physiology. We have not made any progress in ascertaining the first principles of human physiology as the basic scientific underpinning Neonatology, other than to amass volumes of clinical information as an empiric guide for managing preterm infants it must be underscored that there is a fundamental difference between information and knowledge.

Now, armed with molecular biologic methods - genomics, proteomics, metabolomics, phenomics, etc. - we must determine what principles determine the processes of physiologic adaptation at the cell-molecular, tissue, organ, systemic, and organismal levels if we are to fulfill the ultimate, and lofty 
goal of Neonatology - for every newborn to achieve its genetic destiny. That is the Grand Challenge. When Mary Ellen Avery invited me as a basic scientist to join her research group as it transitioned from McGill University to Harvard Medical School in 1974, she said to me "we need to provide science as the foundation for Neonatology, or we could do a lot of harm in the name of good.” Frontiers in Pediatrics: Neonatology is dedicated to the on-going reporting and encouragement of that effort.

\section{REFERENCES}

1. Baker JP. The incubator and the medical discovery of the premature infant. J Perinatol (2000) 20:321-8.

2. Hess JH. Premature and Congenitally Diseased Infants. New York: Lea and Febiger (1922).

3. Diczfalusy E. Endocrine functions of the human fetoplacental unit. Fed Proc (1964) 23:791-8.

4. Taussig HB, Kallman CH, Nagel D, Baumgardner R, Momberger N, Kirk H. Long-time observations on the Blalock-Taussig operation VIII. 20 to 28 year follow-up on patients with a tetralogy of Fallot. Johns Hopkins Med J (1975) 137:13-9.
5. Liley AW. Liquor amnii analysis in management of pregnancy complicated by rhesus immunization. Am J Obstet Gynecol (1961) 82:1359-71.

6. Gluck L, Kulovich MV. Lecithin-sphingomyelin ratios in amniotic fluid in normal and abnormal pregnancy. Am J Obstet Gynecol (1973) 115:539-46.

7. Gregory GA, Edmunds LH Jr, Kitterman JA, Phibbs $\mathrm{RH}$, Tooley WH. Continuous positive airway pressure and pulmonary and circulatory function after cardiac surgery in infants less than three months of age. Anesthesiology (1975) 43:426-31. doi: 10.1097/00000542-197510000-00008

8. Liggins GC, Howie RN. A controlled trial of antepartum glucocorticoid treatment for prevention of the respiratory distress syndrome in premature infants. Pediatrics (1972) 50:515-25.

9. Shapiro DL, Notter RH, Horin FC III, Deluga KS, Golub LM, Sinkin RA, et al. Double-blind, randomized trial of a calf lung surfactant extract administered at birth to very premature infants for prevention of respiratory distress syndrome. Pediatrics (1985) 76:593-9.

10. Avery ME, Mead J. Surface properties in relation to atelectasis and hyaline membrane disease. AMA J Dis Child (1959) 97:517-23.

11. Liggins GC, Howie RN.A controlled trial of antepartum glucocorticoid treatment for prevention of the respiratory distress syndrome in premature infants. Pediatrics (1972) 50:515-25.

12. Apgar V. A proposal for a new method of evaluation of the newborn infant. Curr Res Anesth Analg (1953) 32:260-7.

13. Lubchenco LO, Hansman C, Dressler M, Boyd E. Intrauterine growth as estimated from liveborn birth-weight data at 24 and 42 weeks of gestation. Pediatrics (1963) 32:793-800.

14. Richardson DK, Gray JE, McCormick MC, Workman K, Goldmann DA. Score for neonatal acute physiology: a physiologic severity index for neonatal intensive care. Pediatrics (1993) 91:617-23.

Received: 22 April 2013; accepted: 07 June 2013; published online: 08 July 2013.

Citation: Torday JS (2013) Neonatology specialty grand challenge. Front. Pediatr. 1:13. doi: 10.3389/ fped.2013.00013

This article was submitted to Frontiers in Neonatology, a specialty of Frontiers in Pediatrics.

Copyright (c) 2013 Torday. This is an open-access article distributed under the terms of the Creative Commons Attribution License, which permits use, distribution and reproduction in other forums, provided the original authors and source are credited and subject to any copyright notices concerning any thirdparty graphics etc. 